\title{
DETERMINING BUSINESS INTELLIGENCE USAGE SUCCESS
}

\author{
Javier N. Montero and Mary L. Lind \\ Defense Information Systems Agency, USA \\ Louisiana State University Shreveport, USA
}

\begin{abstract}
Business intelligence systems are highly complex systems that senior executives use to process vast amounts of information when making decisions. Business intelligence systems are rarely used to their full potential due to a poor understanding of the factors that contribute to system success. Organizations using business intelligence systems frequently find that it is not easy to evaluate the effectiveness of these systems, and researchers have noted that there is limited scholarly and practical understanding of how quality factors affect information use within these systems. This quantitative post positivist research used the information system (IS) success model to analyze how information quality and system quality influence information use in business intelligence systems. This study was also designed to investigate the moderating effects of maturity constructs (i.e., data sources and analytical capabilities) on the relationships between quality factors and information use.
\end{abstract}

\section{KEYWORDS}

Business Intelligence, information quality, system quality, systems maturity

\section{INTRODUCTION}

Business intelligence systems support organizational decision-making processes by allowing decision makers to store, access, and analyze important data (Dooley et 1, 2018; Eybers \& Giannakopoulos, 2015). Through the use of descriptive and predictive techniques, business intelligence systems allow decision-makers to evaluate data on customers, competitors, business environments, and business processes to achieve competitive advantage. However, business intelligence models are not well understood, and there is limited research on the overall effectiveness and success of these systems. The study was conducted to determine whether information quality and business intelligence system quality significantly impact the overall success of business intelligence systems.

\section{REVIEW OF THE LITERATURE}

Studies show that business intelligence systems provide value to organizations, but system success is not always quantifiable (Visinescu et al., 2016). To address this issue, the information systems (IS) success model (DeLone \& McLean, 2016) aided in the formation of a theoretical foundation to examine the relationships between information and business intelligence system quality and system success measured by information use. The information systems success model is one of the most popular and influential frameworks used by researchers to measure the success of information systems (Visinescu et al., 2016). The IS success model is based on the assumption that overall system use is indicative of information system success (Mardiana et al., 2015). 


\subsection{Business Intelligence Systems}

Business intelligence systems are a collection of information technologies that enable organizations to make more efficient and informed decisions resulting in improved performance outcomes (Foshay et al., 2014). These information technologies include applications and processes that allow data consolidation, storage, retrieval, and analysis. The information processed by business intelligence systems is multidimensional and comes from many heterogeneous sources (e.g., databases, search engines, data warehouses, and external and internal sources). The data processed by these systems exist in various levels of quality, formatting, and type.

\subsection{DeLone \& McLean IS Success Model}

Information system success is hard to define due to the inherent complexities, interdependencies, and multi-dimensional make-up of a successful system (DeLone, \& McLean, 2016). DeLone and Mclean (2003) developed the IS success model based on the idea that information system success is dependent on six variables: (a) system quality, (b) information quality, (c) service quality, (d) intention to use/use, (e) user satisfaction, and (f) net benefits. Information quality refers to the format, relevance, and usefulness of the information; system quality refers to the level of readiness of the system; and service quality refers to how well the system responds to users' needs.

\subsection{Information Quality}

Information quality is an important consideration when trying to understand business intelligence system success. Business intelligence systems process raw data with high levels of uncertainty and produce analytical data with a high degree of reliability (Appelbaum, Kogan, Vasarhelyi, \& Yan, 2017; Popovič et al., 2012, 2014). For this reason, information quality is critical. The concept of information quality refers to the accuracy, completeness, presentation, and objectivity of the information being used. Report outputs are the basis for information quality measurement, demonstrating overall system effectiveness to the user (Popovič et al., 2014).

Although information quality is considered to be one of the leading factors influencing information use, previous studies have shown mixed support for this relationship (Hackney et al., 2015). Past studies have indicated that information quality could be critical when analyzing vast amounts of complex data (Visinescu et al., 2016). However, information quality is not the only factor that affects business intelligence systems. Information systems studies show that in addition to information quality, system quality also affects system use ( Hackney et al., 2015; Yeoh \& Koronios). The following section addresses the scholarly literature on system quality.

\subsection{System Quality}

System quality focuses on the desirable features and characteristics of a system (Popovič et al., 2014) where system quality is measured in terms of error-free output (Peters et al., 2016). System quality encompasses the integration of applications, databases, and processes that provide accurate and highly reliable information during decision making (Peters et al., 2016). Due to the complexity and integrated nature of these systems, the implementation of business intelligence systems enhancements is more effective when the focus is on the system or organization as a whole (Peters et al., 2016). 
Data quality is an integral component in systems quality and is comprised of four dimensions: (a) intrinsic data quality, (b) accessibility data quality, (c) contextual data quality, and (d) representation data quality. These dimensions are impacted by the fact that data comes from heterogeneous sources that vary in quality, are inconsistent in representation, and come in various formats that may require translation and clarification (Peters et al., 2016). The first dimension, intrinsic data quality covers data accuracy, objectivity, believability, and reputation. Accessibility addresses the physical and security concerns regarding access to information for decision making (Grublješič \& Jaklič, 2015). Contextual data quality is the currency, timeliness, sufficiency, and relevancy of the information. If the right type of data is not available at the right time, then the quality of the resulting analyses could be compromised. Sufficiency and relevancy address the completeness of the data as its appropriateness to supporting the analytic mission at hand. The fourth dimension of data quality is representation where representation data quality refers to users' ability to interpret and understand the data. Data must adequately encapsulate all four dimensions of data quality to ensure system quality (Hackney et al., 2015).

\subsection{Information Use}

Information use within systems has been researched extensively within the context of technology acceptance, with most of the research emphasizing application use (Bach, Čeljo, \& Zoroja, 2016). Prior systems adoption research has focused on the characteristics of success, acceptance, implementation, and the ability to make decisions. The emphasis on application use highlights the need to study information use holistically as a system within the organization (Olszak, 2016).

There is a distinct difference between business intelligence system use and user activities leading to acceptance of the system (Grublješič \& Jaklič, 2015). Similar to any other application or system, the success of business intelligence systems can be measured by users' intentions and the system's ability to provide timely and accurate business intelligence (Popovič et al., 2012).

\subsection{System Maturity}

Business intelligence systems can be differentiated from other information technologies in that the focus of a business intelligence system is on the analysis of data coming from different sources both inside and outside an organization. The output of a business intelligence system is quality information that can be used to aid in decision making. Organizations implementing information technology need a method to evaluate performance and availability. Popovič et al. (2009) identified two maturity dimensions specific to business intelligence systems: (a) data integration (data sources) and (b) analytics where the level of maturity affects the quality of the information used in these systems.

Maturity plays an essential factor in the readiness and reliability of business intelligence systems (Hackney et al., 2015). In the context of business intelligence, analytical capabilities and data sources form a method for measuring the maturity of the system (Popovič et al., 2012). Analytical capabilities maturity is measured by determining how effective a system is at analyzing information obtained from products such as papers and ad-hoc reports, online analytical processing, data mining, performance metrics, alerts, and dashboards (Popovič et al., 2012). Data sources maturity is measured by focusing on the level of integration and consistency of data from diverse sources such as data warehouses, data marts, spreadsheets, databases, or other applications containing data (Popovič et al., 2012). 


\subsection{Critique of Previous Research Methods}

Based on previous research, the present study hypothesized that success of a business intelligence system is linked to its use and its perceived benefits to the organization. Previous research on system success primarily focused on individual information systems, and very little research has examined the factors influencing the success of business intelligence systems (Hackney et al., 2015)

Studies argue that the IS success model (DeLone \& McLean, 2003) fails to account for nontechnological factors such as system management or business needs when evaluating system success (Adamala \& Cidrin, 2011) where they explained that nontechnological factors such as objectives and processes are of more significance to the success of a business intelligence system than technological factors. Yeoh and Koronios (2010) also noted that contextual issues surrounding the implementation of a business intelligence system must be taken into consideration when evaluating system success. A follow-up Delphi case study conducted by Yeoh and Popovič (2016) confirmed the need to maintain cognizance of contextual (i.e., nontechnological) issues in order to make business intelligence systems successful with further research on critical success factors affecting these systems. Though organizational leaders feel that business intelligence provides value, understanding how to quantify success and measure net benefits to the organization requires additional study (Baker \& Chasalow, 2015). Existing research indicates that information quality and system quality are essential factors in understanding the success of a business intelligence system, and researchers have argued that developing a better understanding of the interrelationship amongst these factors would make the success of business intelligence systems easier to measure (Even et al., 2015).

\subsection{Overarching Research Question and Design}

The overarching research question addressed in this study: To what extent do information quality andbusiness intelligence system quality relate to the success of business intelligence systems measured through information use when moderated by systems maturity?

The model shown in Figure 1 provides a visual representation of the relationship between the study's variables and indicators. The variables, shown as ovals in Figure 1, also represent the construct sequence and proposed relationships within the study. The arrows show the relationship between information quality and business intelligence system quality (exogenous constructs) with information use (endogenous construct). Hair (2016) explained that exogenous constructs depict independent variables while endogenous constructs depict dependent variables. The ovals representing information quality and system quality show arrows pointing to them from their respective indicators representing a formative measurement model showing a cause-effect relationship with the independent variable. The arrows pointing toward information use show the measured influence of the two independent variables (i.e., information quality and system quality). 


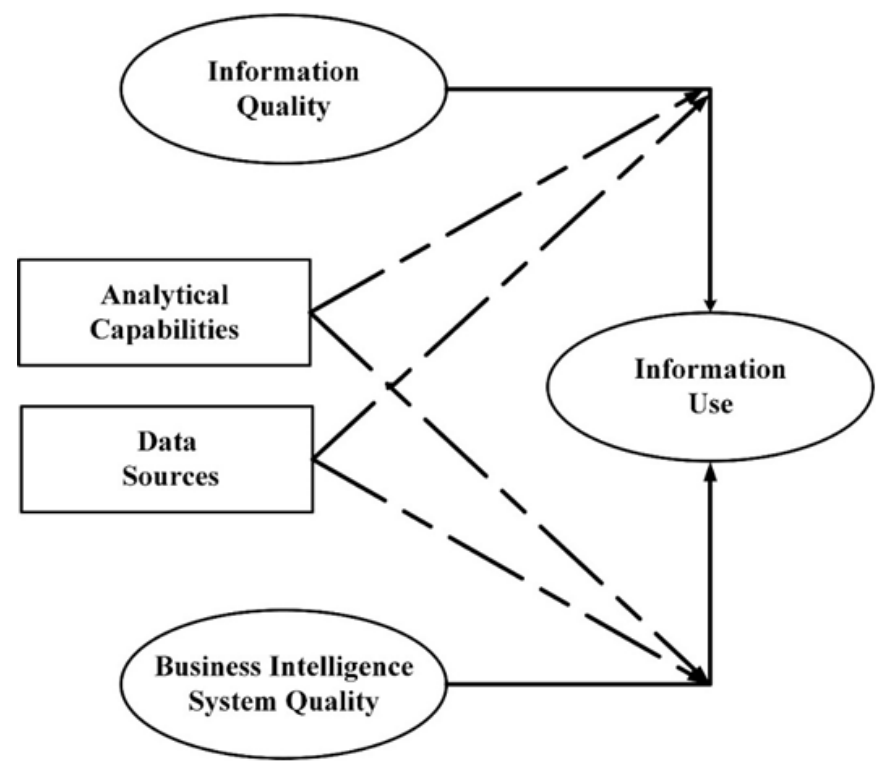

Figure 1. Relationships between constructs and their corresponding indicators. Adapted with permission from "How Information-Sharing Values Influence the Use of Information Systems: An Investigation in the Business Intelligence Systems Context," by A. Popovič, R. Hackney, P. S. Coelho, and J. Jaklič, 2014, The Journal of Strategic Information Systems, 23, p. 273. Copyright 2014 by Elsevier B.V.

Subquestion 1: What is the relationship between information quality and business intelligence system success measured through information use?

Subquestion 2: What is the relationship between business intelligence system quality and business intelligence system success measured through information use?

Subquestion 3: What is the relationship between information quality and information use when using the maturity construct data sources as a moderating variable?

Subquestion 4: What is the relationship between information quality and information use when using the maturity construct analytical capabilities as a moderating variable?

Subquestion 5: What is the relationship between system quality and information use when using the maturity construct data sources as a moderating variable?

Subquestion 6: What is the relationship between system quality and information use when using the maturity construct analytical capabilities as a moderating variable?

\section{Model Evaluation}

The study utilized a quantitative correlational design to measure the relationship between information quality and system quality on information use using a postpositivist research philosophy. A validated survey instrument developed by Popovič et al. (2014) was used to collect data from individuals who were representative of the study's target population. The sample consisted of a randomly selected cross-section of 109 senior business executives (i.e., CEOs, CIOs, CTOs, and information technology managers) who employ business intelligence systems as part of their daily decision-making processes. The study excluded respondents that did not use business intelligence systems to plan, analyze, or make business decisions.

The model shown in Figure 2 provides a visual representation of the relationship between the study's variables and indicators 


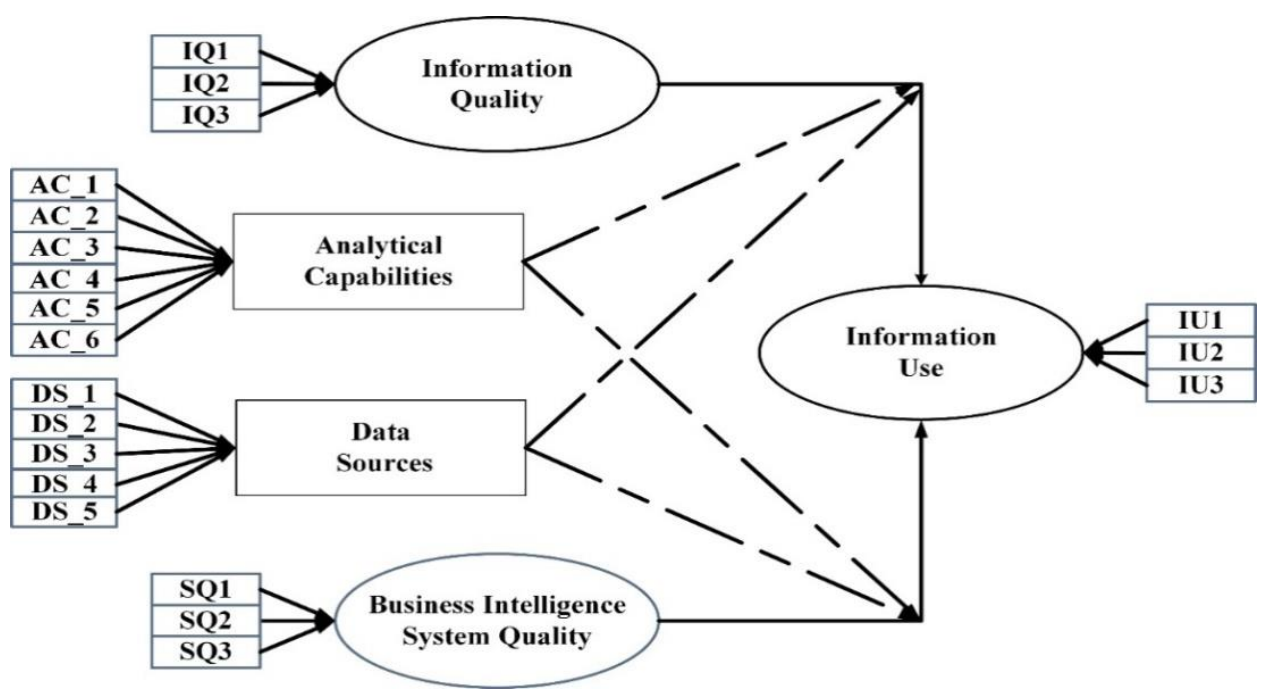

Figure 2. Relationships between constructs and their corresponding indicators. Adapted with permission from "How Information-Sharing Values Influence the Use of Information Systems: An Investigation in the Business Intelligence Systems Context," by A. Popovič, R. Hackney, P. S. Coelho, and J. Jaklič, 2014, The Journal of Strategic Information Systems, 23, p. 273. Copyright 2014 by Elsevier B.V.

As part of the examination of descriptive statistics, each respondent answered a series of system maturity questions associated with the available business intelligence system. Measuring system maturity allowed for a clearer understanding of the use of business intelligence systems within the sample. Table 1 shows the organization of system maturity components used in the survey.

Table 1. Maturity Constructs, Variables, and Items (7 Point Likert Scale)

\begin{tabular}{|c|c|c|c|}
\hline Construct & Variable & $\begin{array}{l}\text { Item } \\
\text { Number }\end{array}$ & Question \\
\hline \multirow[t]{5}{*}{ Data Sources } & \multirow[t]{5}{*}{ DS } & DS1 & $\begin{array}{l}\text { To what extent are Transactional System(s) used in your } \\
\text { organization? }\end{array}$ \\
\hline & & DS2 & $\begin{array}{l}\text { To what extent are spreadsheets, databases used in your } \\
\text { organization? }\end{array}$ \\
\hline & & DS3 & $\begin{array}{l}\text { To what extent are data warehouse(s), including data marts used in } \\
\text { your organization? }\end{array}$ \\
\hline & & DS4 & $\begin{array}{l}\text { Data are completely integrated, enabling real-time reporting and } \\
\text { analysis }\end{array}$ \\
\hline & & DS5 & Data in the sources are mutually consistent \\
\hline Analytical & \multirow[t]{6}{*}{$\mathrm{AC}$} & $\mathrm{AC} 1$ & To what extent are paper reports used in your organization? \\
\hline \multirow[t]{5}{*}{ Capabilities } & & $\mathrm{AC} 2$ & $\begin{array}{l}\text { To what extent are interactive reports (ad-hoc) used in your } \\
\text { organization? }\end{array}$ \\
\hline & & AC3 & $\begin{array}{l}\text { To what extent are on-line analytical processing (OLAP) used in } \\
\text { your organization? }\end{array}$ \\
\hline & & $\mathrm{AC} 4$ & $\begin{array}{l}\text { To what extent are analytical applications, including trend analysis, } \\
\text { "what-if" scenarios used in your organization? }\end{array}$ \\
\hline & & AC5 & To what extent is data mining used in your organization? \\
\hline & & AC6 & $\begin{array}{l}\text { To what extent are dashboards, including metrics, key } \\
\text { performance indicators (kpi), alerts used in your organization? }\end{array}$ \\
\hline
\end{tabular}

Note. $\mathrm{DS}=$ data sources, and AC = analytical capabilities.

The survey used in the present study contained a total of 29 questions. Six questions asked respondents to provide demographic information regarding their age, education level, industry 
type, the number of employees in their organization, the number of years they spent working on business intelligence systems, and the type of involvement they had in business intelligence. Demographic questions focused on the respondents' background and experience with business intelligence systems. Similar to the Popovič et al. (2014) study, respondents in the study answered 11 system maturity questions and 12 questions relating to the variables used in Popovič et al.'s (2014) study.

Validity. The validity of the instrument used in the Popovič et al. (2014) study followed Fornell's composite reliability (CR) and average variance values (AVE). The CR scores for the variables in this study were information quality $=0.98$, system quality $=0.97$, and information use $=0.94$. All composite reliabilities were above the recommended value of 0.80 (Popovič et al., 2014). The AVE for the constructs was as follows: information quality $=0.95$, system quality $=0.92$, and information use $=0.83$. All values presented an AVE well above the recommended threshold of 0.5 (Fornell \& Larcker, 1981). Wixom and Todd (2005) used reliability, flexibility, integration, accessibility, and timeliness as determinants for measuring overall business intelligence system quality with an AVE of $=0.94$.

Reliability. Popovič et al. (2014) established the reliability of the instrument by using Cronbach's alpha to test the CR of each variable. Popovič et al.'s (2014) analysis yielded an alpha score of 0.97 for information quality, a score of 0.95 for business intelligence system quality, and a score of 0.89 for information use. All three reliability values were above the suggested acceptable value of 0.70 to 0.80 for Cronbach's alpha.

The survey instrument contained nine questions measured on a 7-point Likert scale. Cronbach's alpha coefficients were calculated for the dependent and independent variables to verify the reliability of the instrument. For this study, information quality reported an alpha value of 0.94 , system quality resulted in a value of 0.90 , and information use produced a value of 0.95 . The coefficient resulting from the Cronbach's alpha coefficient analysis for the three constructs combined was 0.95 , indicating excellent reliability. Cronbach's alpha coefficients were also calculated for the moderating variables. The Cronbach's alpha score for analytical capabilities maturity was 0.91 , and the value for data source maturity was 0.93 . Table 2 compares the Cronbach's alpha results between the study and Popovič et al.'s (2014) study.

Table 2. Cronbach's Alpha Scores

\begin{tabular}{lll}
\hline Construct & Present Study & Popovič et al. (2014) \\
\hline IQAvg & 0.94 & 0.97 \\
SQAvg & 0.90 & 0.95 \\
IUAvg & 0.95 & 0.89 \\
AC & 0.91 & 0.76 \\
DS & 0.93 & 0.75 \\
\hline
\end{tabular}

Note. The Cronbach's Alpha coefficient for the combined independent and dependent variables was 0.95. The Cronbach's Alpha coefficient for the combined maturity constructs was 0.82. IQAvg = information quality average, SQavg = system quality average, IUavg = information use average, AC = analytical capabilities, and DS = data sources.

\subsection{Correlational Analysis}

The study used two types of correlation analysis to test the hypotheses and answer the research questions. Pearson current moment and partial correlations were used to analyze the linear relationship between the independent and dependent variables and the influence of the maturity 
constructs on those relationships. Correlations analyze the size and direction of the relationship between variables (Keith, 2015). Type I risk level testing at an $\alpha=.05$ was used to determine the likelihood of rejecting the null hypothesis by mistake. Each subquestion was analyzed based on the composite values calculated as part of the descriptive analysis.

Subquestion 1. What is the relationship between information quality and business intelligence system success measured through information use? Studies show that information quality is a significant element in users' willingness to use a business intelligence system (Kowalczyk \& Gerlach, 2015). Subquestion 1 focused on the analysis of information quality as it influences information use. The null hypothesis theorized that information quality, $M(109)=5.96, S D=$ 0.93 , did not have a positive influence on information use, $M(109)=5.99, S D=0.99$. The results of the correlation testing, presented in Table 3 , show that information quality has a very strong positive influence on information use, $r_{\mathrm{p}}=0.89, n=109, p<.000$. This positive influence shows that as information quality increases so does information use. The null hypothesis was rejected as a result.

Subquestion 2. What is the relationship between business intelligence system quality and business intelligence system success measured through information use? System quality focuses on the desirable features and characteristics of the technical aspects of a system (Popovič et al., 2014). System quality focuses on the desirable features of a business intelligence system and is measured on the basis of technical functionality and the suitability of the system to meet users' needs (Yeoh \& Popovič, 2016). Subquestion 2 focuses in the analysis of system quality, $M(109)$ $=6.01, S D=0.90$, as it influences information use, $M(109)=5.99, S D=0.99$. The null hypothesis theorized that system quality does not have a positive influence on information use. The results presented in Table 18 show that information quality had very strong positive influence on information use, $r_{\mathrm{p}}=0.82, n=109, p<.000$. This positive influence shows that as system quality increases so does information use. The null hypothesis was discarded as a result of the strong significant relationship.

Table 3. Pearson Correlation for IQ, SQ, and IU

\begin{tabular}{lllll}
\hline & & SQAVG & IQAVG & IUAVG \\
\hline SQAvg & Pearson Correlation & 1 & .909 & .819 \\
& Sig. (2-tailed) & & .000 & .000 \\
& N & 109 & 109 & 109 \\
IQAvg & Pearson Correlation & .909 & 1 & .891 \\
& Sig. (2-tailed) & .000 & & .000 \\
& N & 109 & 109 & 109 \\
IUAvg & Pearson Correlation & .816 & .891 & 1 \\
& Sig. (2-tailed) & .000 & .000 & \\
& $\mathrm{~N}$ & 109 & 109 & 109 \\
\hline
\end{tabular}

Note. Correlation is significant at the 0.01 level (2-tailed). SQ = system quality, IQ = information quality, and IU = information use., SQUAVG $=$ the average scores for system quality, IQAVG $=$ the average scores for information quality, and IUAVG $=$ the average scores for information use.

Subquestion 3. What is the relationship between information quality and information use when using the maturity construct data sources as a moderating variable? System maturity is defined as a system fully developed and implemented within the organization (Popovič et al., 2012). Popovič et al. (2012) researched the level of maturity to understand data sources and analytical capabilities. The null hypothesis for Subquestion 3 theorized that there is no relationship between information quality and information use when moderating for the maturity construct data sources. The partial correlation results show that there is a strong relationship between IQAvg and IUAvg 
when moderating for the data sources maturity construct. There was a strong, positive partial correlation between information quality, $M(109)=5.96, S D=.93$, and information use, $M(109)=$ $5.99, S D=0.99$, when moderating for DSMaturity, $M(109)=5.58, S D=1.37$. The correlation was statistically significant, $r(104)=.775, n=109, p=.000$.

The scatterplot shown in Figure 3 indicates that the relationship between the variables was positive and linear. The relationship demonstrates that an increase in information use based on information quality shows a strong increase when controlling for the maturity construct direct sources. The null hypothesis theorizing that there is no relationship between information quality and information use when controlling for data sources was therefore rejected. Table 4 shows the results of the partial correlation analysis when controlling the relationship between information use and information quality with the maturity construct data sources.

Table 4. Partial Correlation for IU and IQ When Controlling for DSMaturity

\begin{tabular}{llll}
\hline Control & Constructs & Tests & Values \\
\hline DSMaturity & IUAVG & Correlation & .775 \\
& IQAVG & Significance (2-tailed) & .000 \\
& & df & 106 \\
\hline
\end{tabular}

Note. DSMaturity $=$ data sources maturity, IUAVG $=$ the average scores for information use, and IQAVG $=$ the average scores for information quality.

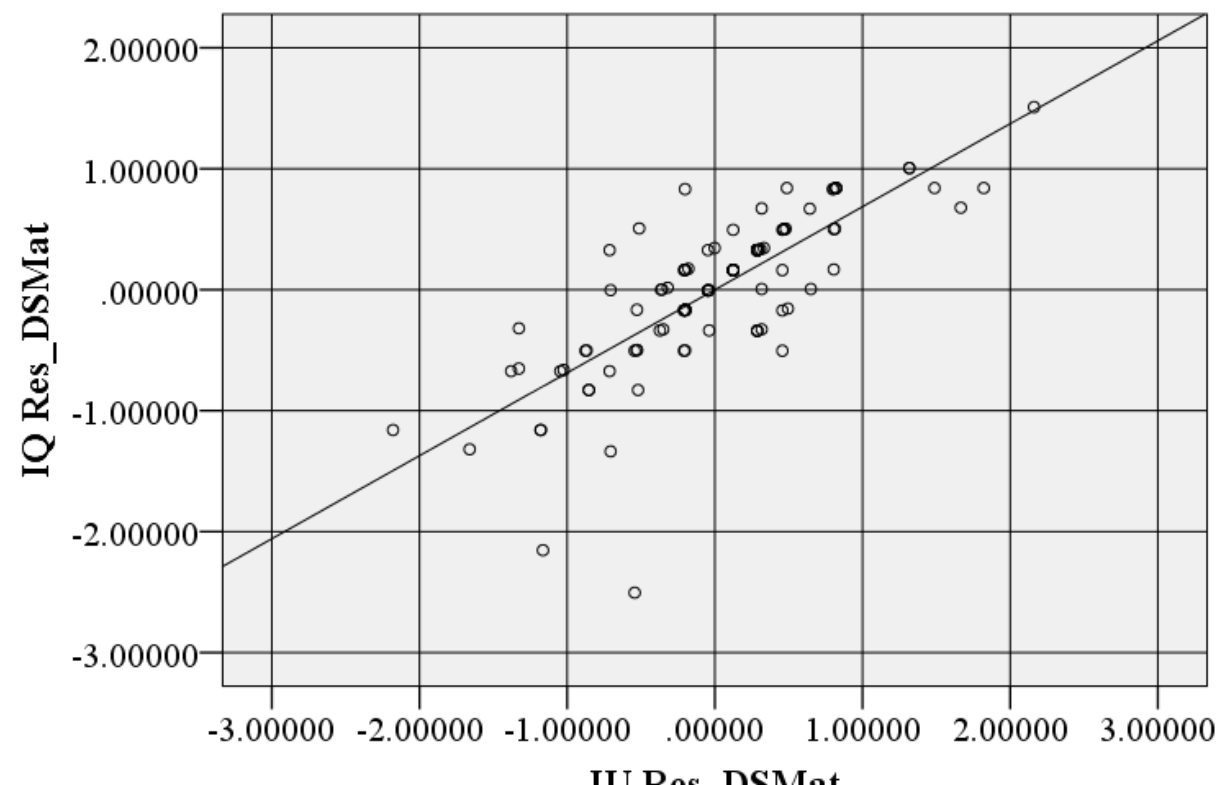

IU Res_DSMat

Figure 3. Residual scatterplot of IU and IQ moderated by DSMaturity. IU = information use, IQ = information quality, and DS = data sources. The residual scatterplot is showing the relationship between IU and IQ when moderated by DSMaturity. The Y-axis represents IQ, and the X-axis represents IU with both variables moderated by DSMaturity. The plot shows a positive linear relationship between both variables when moderated by DSMaturity.

Subquestion 4. What is the relationship between information quality and information use when using the maturity construct analytical capabilities as a moderating variable? The null hypothesis theorizes that there is no relationship between information quality and information use when moderating for the maturity construct analytical capabilities. The analysis indicated there was a 
strong, positive partial correlation between IUAvg, $\mathrm{M}(109)=5.96, \mathrm{SD}=.93$, and IQAvg, $\mathrm{M}(109)=6.01, \mathrm{SD}=0.90$, when moderating for ACMaturity, $\mathrm{M}(109)=5.39, \mathrm{SD}=1.37$. The relationship was statistically significant, $\mathrm{r}(104)=.839, \mathrm{n}=106, \mathrm{p}=.000$.

The scatterplot shown in Figure 4 shows that this relationship is both positive and linear. The relationship demonstrates that an increase in information use based on information quality shows a strong increase when controlling for the maturity construct analytic capabilities. The null hypothesis was rejected. Table 5 shows the results of the partial correlation analysis of the relationship between information use and information quality when controlling for the maturity construct analytical capabilities

Table 5. Partial Correlation for IU and IQ When Controlling for ACMaturity

\begin{tabular}{llll}
\hline Control & Constructs & Tests & Values \\
\hline ACMaturity & IUAVG & Correlation & .839 \\
& IQAVG & Significance (2-tailed) & .000 \\
& & $d f$ & 106 \\
\hline
\end{tabular}

Note. ACMaturity = analytic capabilities maturity, IUAVG = the average scores for information use, and $\mathrm{IQAVG}=$ the average scores for information quality.

Subquestion 5. What is the relationship between system quality and information use when using the maturity construct data sources as a moderating variable? The null hypothesis theorizes that there is no relationship between system quality and information use when moderating for the maturity construct data sources. The partial correlation results show that there was a strong relationship between SQAvg and IUAvg when moderating for the data sources maturity construct. There was a strong, positive partial correlation between IUAvg, $M(109)=5.96, S D=$ .93 , and SQAvg, $M(109)=6.01, S D=0.90$, when moderating for DSMaturity, $M(109)=5.58, S D$ $=1.37$. The relationship was statistically significant, $r(104)=.636, n=106, p=.000$, as shown in Table 21.

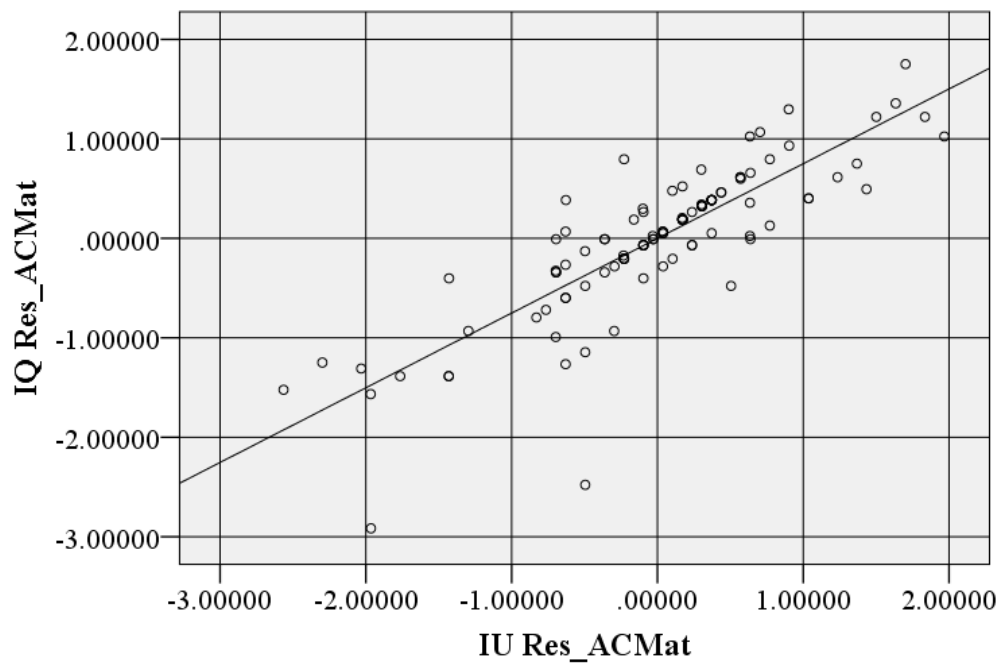

Figure 4. Residual scatterplot of IU and IQ moderated by ACMaturity. IU = information use, IQ = information quality, and $\mathrm{AC}=$ analytical capabilities. The residual scatterplot is showing the relationship between IU and IQ when moderated by ACMaturity. The Y-axis represents IQ, and the X-axis represents IU with both variables moderated by ACMaturity. The plot shows a positive linear relationship between the variables when moderated by ACMaturity. 
Table 6. Partial Correlation for IU and SQ When Controlling for DSMaturity

\begin{tabular}{llll}
\hline Control & Constructs & Tests & Values \\
\hline DSMaturity & IUAVG & Correlation & .636 \\
& SQAVG & Significance (2-tailed) & .000 \\
& $d f$ & 106 \\
\hline
\end{tabular}

Note. DSMaturity = data sources maturity, IUAVG = the average scores for information use, and $\mathrm{SQAVG}=$ the average scores for system quality.

The scatterplot presented in Figure 5 shows that the relationship between system quality and information use was positive and linear even when moderated by the data sources maturity construct. The scatterplot demonstrates that a strong increase in information use based on system quality was demonstrated even when controlling for the maturity construct data sources. The null hypothesis was rejected as a result.

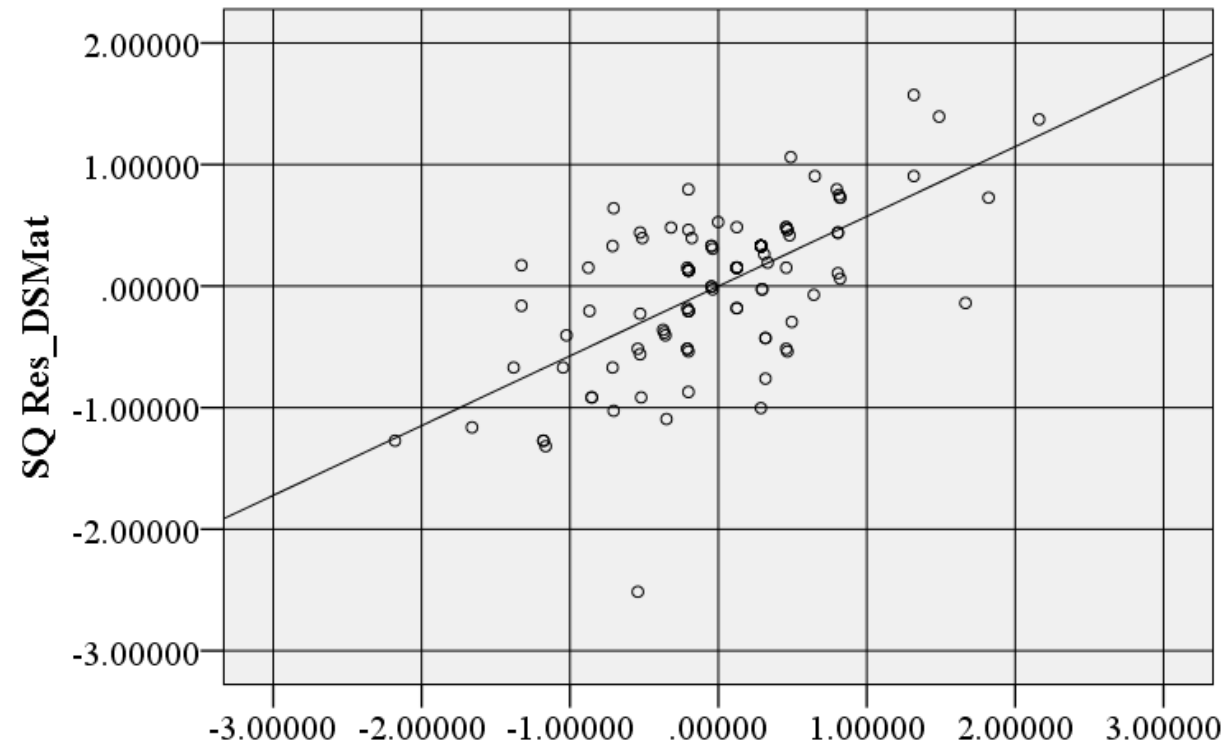

IU Res_DSMat

Figure 5. Residual scatterplot of IU and SQ moderated by DSMaturity. IU= information use, SQ = system quality, and DS = data sources. The residual scatterplot is showing the relationship between IU and SQ

when moderated by DSMaturity. The Y-axis represents IQ, and the X-axis represents IU with both variables moderated by DSMaturity. The plot shows a positive linear relationship between the variables when moderated by DSMaturity.

Subquestion 6. What is the relationship between system quality and information use when using the maturity construct analytical capabilities as a moderating variable? The null hypothesis theorized that there is no relationship between system quality and information use when moderating for the maturity construct analytical capabilities. The partial correlation results indicated that there was a strong, positive partial correlation between IUAvg, $M(109)=5.96, S D$ $=.93$, and SQAvg, $M(109)=6.01, S D=0.90$, when moderating for ACMaturity, $M(109)=5.39$, $S D=1.37$. This result was statistically significant, $r(104)=.729, n=106, p=.000$.

The relationship between system quality and information use was positive and linear. The relationship demonstrates that an increase in information use was observed based on an increase 
in system quality even when controlling for the maturity construct analytical capabilities. The null hypothesis was rejected. Table 7 shows the results of the partial correlation analysis when controlling the relationship between information use and system quality with the maturity construct analytical capabilities.

Table 7. Partial Correlation for IU and SQ Controlling for ACMaturity

\begin{tabular}{llll}
\hline Control & Constructs & Tests & Values \\
\hline ACMaturity & IUAVG & Correlation & .729 \\
& SQAVG & Significance (2-tailed) & .000 \\
& & df & 106 \\
\hline
\end{tabular}

Note. ACMaturity = analytical capabilities maturity, IUAVG $=$ the average scores for information use, and $\mathrm{SQAVG}=$ the average scores for system quality.

\subsection{Summary of Hypothesis Testing}

The null hypotheses for all six subquestions were rejected, as strong, statistically significant relationships were observed amongst the study's variables. The Pearson correlation analysis shows that strong, positive linear relationships existed between information quality and information use and between system quality and information use. There was a significant positive correlation between SQAvg and IUAvg, $r_{\mathrm{p}}=0.82, p<.001$, indicating a large effect size, and as SQAvg increased, IUAvg also increased. There was a significant positive correlation between IQAvg and IUAvg, $r_{\mathrm{p}}=0.89, p<.001$. This relationship also showed a large effect size, and as IQAvg increased, IUAvg also increased. Figure 6 shows a linear tendency between the independent constructs, information quality and system quality, and the dependent construct, information use.

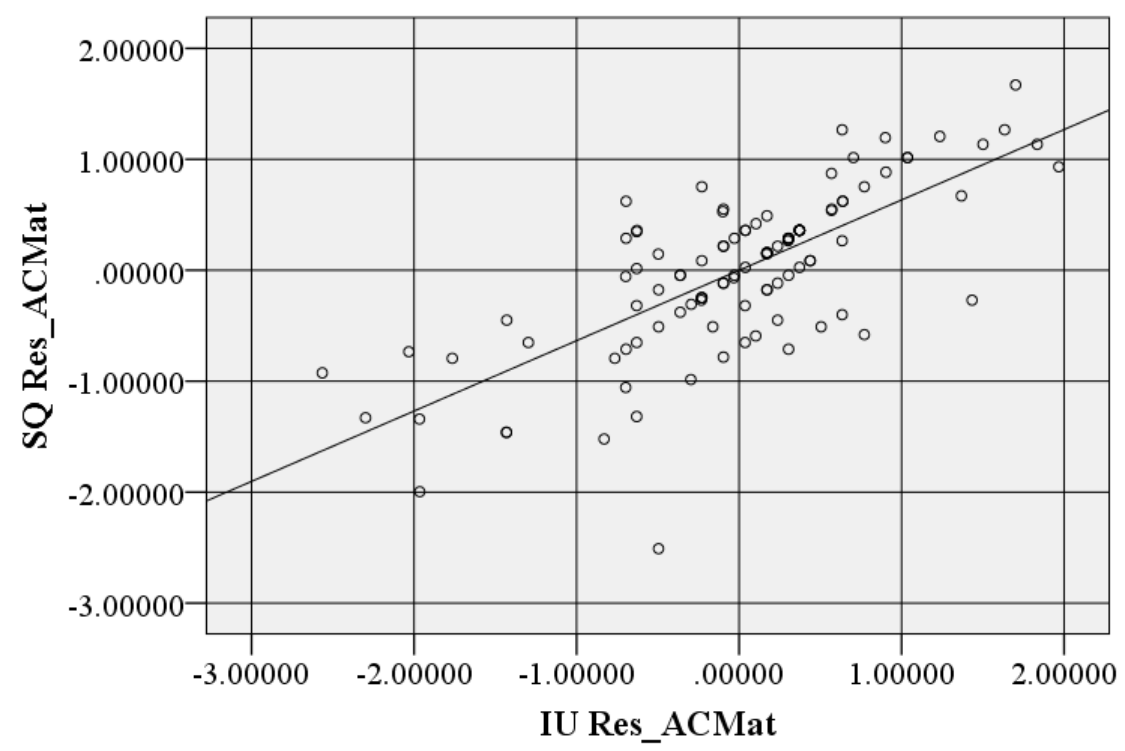

Figure 6. Residual scatterplot of IU and SQ moderated by ACMaturity. IU = information use, $\mathrm{SQ}=$ system quality, and $\mathrm{AC}=$ analytical capabilities. The residual scatterplot is showing the relationship between IU and SQ when moderated by ACMaturity. The Y-axis represents IQ, and the X-axis represents IU with both variables moderated by ACMaturity. The plot shows a positive linear relationship between the variables when moderated by ACMaturity. 
A partial correlation was run to introduce the effects of the maturity constructs direct sources and analytical capabilities. Figures 7 and 8 show an overlay of the partial correlations when moderating for the maturity constructs. The overlays show the residual scatterplots for the relationships between information and system quality and information use while moderated by DSMaturity, $r(104)=.775, N=109, p=.000$, and the scatterplot for the relationships between information and system quality and information use while moderating for ACMaturity, $r(104)=$ $.839, N=106, p=.000$. These figures demonstrate that both relationships have similar linear positive relationships as the values change. The results of the partial correlations demonstrate statistical significance for all variables when controlling for data sources and analytical capabilities separately. The resulting coefficients demonstrate that all variables affect each other when moderated by maturity.

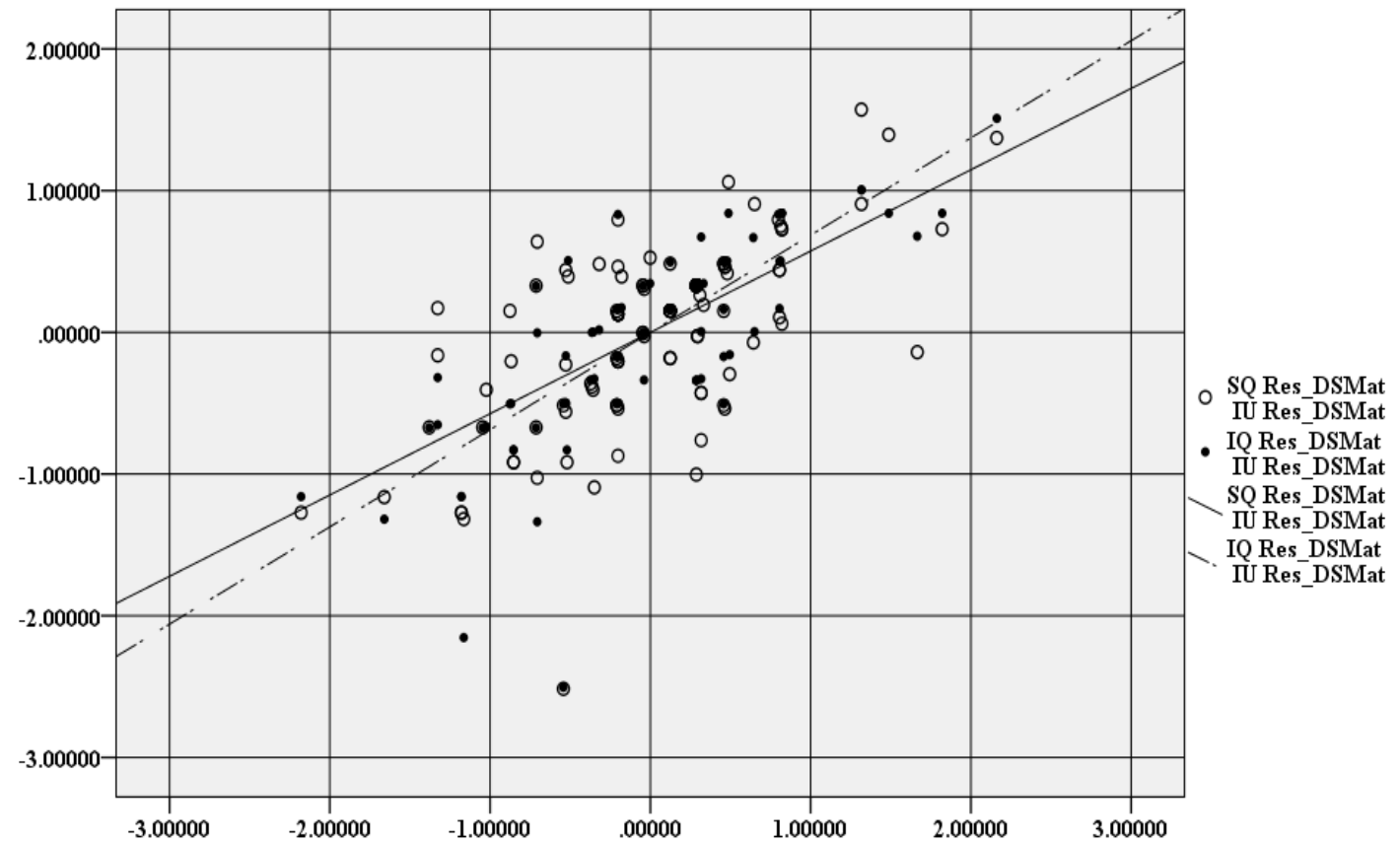

Figure 7. Scatter plot overlay for IQ-IU and SQ-IU moderated by DSMaturity. IQ = information quality, IU = information use, $\mathrm{SQ}=$ system quality, $\mathrm{DS}=$ data sources. The solid circles represent the relationship of IQ and IU when moderated by DSMaturity. The outlined circles represent the relationship between SQ and

IU when similarly moderated by DSMaturity. The dashed regression line shows a positive linear relationship between IQ and IU when moderated by DSMaturity. The solid regression line shows the linear relationship for SQ and IU when moderated for DSMaturity. The overlay demonstrates that both relationships have a strong positive relationship when controlled by DSMaturity. 


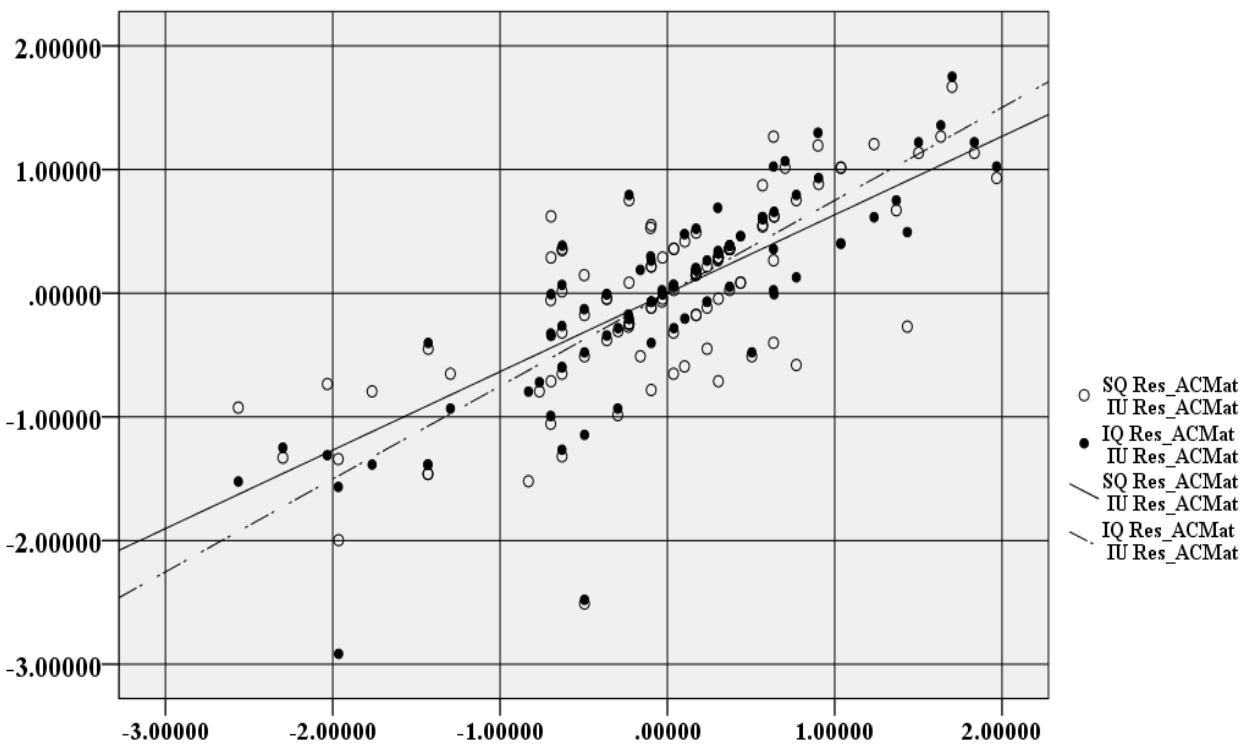

Figure 8. Scatter plot overlay for IQ-IU and SQ-IU moderated by ACMaturity. IQ = information quality, $\mathrm{IU}=$ information use, $\mathrm{SQ}=$ system quality, $\mathrm{AC}=$ analytical capabilities. The solid circles represent the relationship between IQ and IU when moderated by ACMaturity. The outlined circles represent the relationship between SQ and IU when similarly moderated by ACMaturity. The dashed regression line shows a positive linear relationship between IQ and IU when moderated by ACMaturity. The solid regression line shows the linear relationship for SQ and IU when moderated for ACMaturity. The overlay demonstrates that both relationships have a strong positive relationship when controlled by ACMaturity.

\subsection{Summary of the Results}

Business intelligence systems consist of a combination of different technologies used in the decision-making process of the organization. Business intelligence systems often combine nonconventional applications with enterprise-level projects like enterprise resource planning (ERP) and customer relationship management (CRM) to create an analysis environment able to support decision making (Dooley et al., 2018). The high level of complexity makes it difficult for senior management to gauge the success of business intelligence systems, and standard metrics may not always be effective when measuring system success (Dooley et al., 2018). Scholars have recommended that factors related to system implementation, processes, and maturity be evaluated to better understand system success (Visinescu et al., 2016).

The literature suggests that in order to accurately measure business intelligence system success, it is necessary to understand the structure of the value creation process (Fink et al., 2017). Business intelligence systems are dependent on quality processes that support intelligent decision making (Trieu, 2017). Trieu (2017) argued that the majority of the research on business intelligence does not consider the complexities of the information analysis processes or how factors influence the success of the system.

The present study built upon research conducted by Popovič et al. (2014) to understand the relationship between quality factors that influence the use of information in business intelligence systems. Scholars have noted that it is difficult for businesses to optimize the benefits from business intelligence systems if these systems are not well understood (Even et al., 2015). By investigating how quality factors affect information use, the study contributed to the body of knowledge on the topic and also provided insights that organizations can use when seeking to optimize business intelligence system implementation. Several scholars have argued that because 
of the substantial impact business intelligence systems have on an organization's performance these systems continue to be highly sought after technologies, yet to be truly effective, the systems need further study (Torres, Sidorova, \& Jones, 2018).

Because the benefits of business intelligence systems are difficult to measure scholars have taken different approaches to studying system success (Fink et al., 2017). Scholars have recommended that future research examine specific success factors that influence business intelligence system outcomes (Dooley et al., 2018). Mudzana and Maharaj (2017) examined service quality and found that it significantly influenced the success of business intelligence systems. This study used a similar approach focused on information quality and system quality as potential success factors, and information use served as a measure of system success.

The study utilized a quantitative, postpositive, correlational research methodology to evaluate the relationship between information and system quality and information use as a measure of system success. The study addressed the relationships between the independent and dependent variables using Pearson product moment and partial correlations. The Pearson product moment correlation analyzed the relationships between the quality factors and information use. The partial correlations analyzed the moderating influence of maturity factors (i.e., data sources and analytical capabilities) on the relationship between information and system quality and information use.

Results from the analysis demonstrated the relationships between the independent and dependent variables were statistically significant. This finding supported previous research that indicated that business intelligence systems are highly dependent on quality information derived from quality systems (Arnott et al., 2017). The results also confirmed that the relationships between the independent and dependent variables remained significant even when moderated by maturity levels. Table 8 summarizes the results for the hypotheses tested.

Table 8. Summary of Hypotheses Results

\begin{tabular}{lll}
\hline Subquestion & Hypothesis Number & Result \\
\hline SQ1 & $\mathrm{H}_{0} 1 / \mathrm{H}_{\mathrm{a}} 1$ & Reject the Null \\
SQ2 & $\mathrm{H}_{0} 2 / \mathrm{H}_{\mathrm{a}} 2$ & Reject the Null \\
SQ3 & $\mathrm{H}_{0} 3 / \mathrm{H}_{\mathrm{a}} 3$ & Reject the Null \\
SQ4 & $\mathrm{H}_{0} 4 / \mathrm{H}_{\mathrm{a}} 4$ & Reject the Null \\
SQ5 & $\mathrm{H}_{0} 5 / \mathrm{H}_{\mathrm{a}} 5$ & Reject the Null \\
SQ6 & $\mathrm{H}_{0} 6 / \mathrm{H}_{\mathrm{a}} 6$ & Reject the Null \\
\hline
\end{tabular}

The results demonstrated that the quality factors used to measure success provide a good foundation for evaluating business intelligence systems. The analysis also demonstrated that system maturity has a moderately significant influence on the relationship between quality factors and system success. Based on these findings, the research highlighted a need for further research focused on how individual factors influence the relationship between quality and success when using business intelligence systems to improve organizational decision making.

\subsection{Discussion of the Results}

Previous studies focused on the success of business intelligence systems have examined the performance of the different technologies associated with these systems (Yeoh \& Popovič, 2016). Scholars have argued that business intelligence system success should include the study of 
procedural, organizational, and technological elements of success (Dooley et al., 2018). The present study addressed this concern by investigating the study's central question: To what extent do information quality and business intelligence system quality relate to the success of business intelligence systems measured through information use? The results demonstrated that there is a strong relationship between quality factors and information use. The results also indicated that when controlling for maturity factors, there is a significant influence on the relationship between system and information quality and information use. The following paragraphs provide a discussion of the results organized by subquestion.

Subquestion 1: What is the relationship between information quality and business intelligence system success measured through information use? The results of the study indicated that the null hypothesis for Subquestion 1 should be rejected. A strong positive relationship existed between information quality and information use. Though the study limited the analysis to a countryspecific population and a broad sample of information system users, the results of the analysis support the expectation that changes in information quality would result in similar changes to information use. Though the study did not determine causality, the strong, statistically significant relationship demonstrated that changes in measured levels influence both constructs. As information quality increased, information use also increased, and, as a result, business intelligence systems were more successful. Conversely, business information systems that used less information were more likely to have lower information quality ratings.

Subquestion 2: What is the relationship between business intelligence system quality and business intelligence system success measured through information use? The analysis for Subquestion 2 found that a strong relationship existed between system quality and information use. Thus, the null hypothesis was rejected. The strong, statistically significant relationship between system quality and information use signifies that a change in measured value by either construct affected the other. Though the study did not analyze causality, the results show significant influence in the measured levels. Also, the use of a specific population, senior executives within the United States, showed a relatively mature system implementation in support of business intelligence. While the findings may not represent business intelligence system success at the global scale, this study showed that for the target population, the relationship between information quality and information use was positive and very strong. As system quality increased, information use also increased and, as a result, business intelligence systems were more successful. Conversely, business information systems that used less information were more likely to have lower system quality ratings.

Popovič et al. (2012) theorized that the level of maturity of a business intelligence system, measured through analytical capabilities and data sources, would influence overall system success. A partial correlation analysis was conducted to evaluate the relationship between information quality and system quality while moderating for analytical capability and data source maturity. Popovič et al. (2012) found that the maturity constructs, data sources, and analytical capabilities have a strong influence on the quality of information. The results of the study affirmed Popovič et al.'s (2012) finding by showing that information quality and information use constructs maintained a moderate to strong relationship when accounting for the maturity of a system's data sources and analytical capabilities. The analysis also showed that the maturity of the system influences the relationship amongst the constructs. Subquestions 3 to 6 focus on how maturity influences the relationships between quality and information use.

Subquestion 3: What is the relationship between information quality and information use when using the maturity construct data sources as a moderating variable? A partial correlation analysis was used to determine whether system maturity had a moderating effect on the relationship 
between information quality and information use. The analysis showed that there was indeed a moderately significant relationship between information quality and information use when moderated by the maturity construct data sources. The results led to the rejection of the null hypothesis. The results of this analysis suggest that future research should include factors other than quality to adeqautely understand the relationship between information quality and information success. Additionally, the results support a need to further analyze causality by including factors such as maturity and organizational processes.

Subquestion 4: What is the relationship between information quality and information use when using the maturity construct analytical capabilities as a moderating variable? A partial correlation was conducted to analyze the relationship between information quality and information when moderated by analytical capabilities. The results of the analysis showed a moderately strong relationship between the constructs when using the maturity of analytical capabilities as a moderating variable. The results of this correlation analysis further supported the conclusion that maturity factors do significantly influence the relationship between information quality and information use. As with the results from Subquestion 3, the results from Subquestion 4 support the need for future research into the role of maturity factors and business intelligence system success.

Subquestion 5: What is the relationship between system quality and information use when using the maturity construct data sources as a moderating variable? A partial correlation analysis was used to examine the moderating effect of data sources maturity on the relationship between system quality and information use. Unlike prior research that found no clear evidence with regards to system quality's influence on information use (see Popovič et al., 2014), the study found that system quality does influence information use. When moderated by data sources maturity, the analysis indicated that the relationship between system quality and information use remained significant. This analysis supported the expected results and determined that there is indeed a relationship between system quality and information use that is affected by data sources.

Popovič et al. (2014) found inconclusive results when analyzing system quality and hypothesized that system quality might have an indirect influence on information use. The current analysis supports this possibility by showing that data sources moderate system quality's relationship with information use. The significance of the relationships identified in Subquestions 3 and 5 indicate that an increase in information use based on information and system quality are affected by data source maturity. These findings show how a well implemented and mature system relates to the use of information within the system.

Subquestion 6: What is the relationship between system quality and information use when using the maturity construct analytical capabilities as a moderating variable? A partial correlation analysis was conducted to examine the moderating influence of analytical capabilities on the relationship between system quality and information use. The results indicated the presence of a moderate relationship between system quality and information use when moderating for analytical capabilities. This finding, similar to Subquestion 5, indicated that a well implemented and mature business intelligence system influences the relationship between system quality and information use. The relationship demonstrates that an increase in information use based on system quality increases when controlling for the maturity construct analytical capabilities.

\section{Comparison OF Findings With the TheORETICAL FrameWORK}

The DeLone and McLean's IS success model represents one of the fundamental theories regarding information system success (Gaardboe \& Svarre, 2017). The present study utilized that 
model as a theoretical framework and found that information and system quality are both significantly and positively linked to information use as a measure of business intelligence success. DeLone and Mclean (2003) posited that quality factors have a strong influence on the overall benefits and success of the system, and the study supported that supposition.

Popovič et al. (2014) described a need to analyze business intelligence systems in the context of the system's intended task, which is to generate actionable information used in organizational decision-making processes. Previous research shows that the effect of system and information quality is critical in evaluating usage patterns (Even et al., 2015). Scholars such as Foshay et al. (2014) and Hackney et al. (2015) argued that the IS success model is a useful tool for developing a better understanding of business intelligence systems. The Popovič et al. (2014) study focused on understanding how information quality and system quality influence information use, as a form of success while analyzing the information sharing values of the organization. Though the study did not determine causality, the strong significance between the quality constructs and their association with information use demonstrated a strong linkage to the overall success of the system. Additionally, this study found that the IS success model provides a sound basis for the analysis of business intelligence systems.

\subsection{Interpretation of the Findings}

Research shows that a typical business intelligence system implementation involves technological and organizational processes that interact in the operation of the system (Yeoh \& Popovič, 2016). Thus, individuals responsible for deploying business intelligence systems must consider cross-system functionality requirements, the availability of the system and information within the system, and the fact that data quality can impact the required level of system complexity. Yeoh and Koronios (2010) suggested that organizational processes and technical maturity of the systems present a strong influence in measuring the quality factors that determine the success of the business intelligence system. This study supported this idea by showing that maturity constructs (i.e., analytical capabilities and data sources) influence the relationships between information and system quality and information use. The results of the analysis suggest that maturity levels have a moderate influence on the links between quality and information use.

A business intelligence system is a complex system composed of several technologies employing processes, concepts, and methods to improve the decision-making ability of an organization (Seddon, Constantinidis, Tamm, \& Dod, 2017; Trieu, 2017). Previous studies have explored business intelligence system success by analyzing the performance of the different technologies associated with the system (Işık et al., 2013; Yeoh \& Popovič, 2016). A typical business intelligence system project focuses on the integration of several technologies to form a more extensive data processing system. The quality of the information technologies making up the business intelligence system is critical to both the quality of the system as well as the quality of the information provided by these technologies (Vallurupalli \& Bose, 2018). The results of this study point to a strong relationship between quality factors and the success of the business intelligence systems as measured by information use. The findings highlighted that the definition of quality for a business intelligence system is different from other information systems in that its purpose is to correlate information used to process, analyze, and create decision-making information derived from other information systems (Yeoh \& Popovič, 2016).

The present study demonstrated that maturity factors influence the measurement of quality factors as well as the success of business intelligence systems. This finding aligned with the findings from Popovič et al.'s (2009) study. The study's findings also highlight an increased need to understand other processes that influence how intended users perceive information and system 
quality. The partial correlation analysis showed that maturity factors have a moderate influence on the relationship between quality factors and information use. The results of the partial correlation analysis support the notion that business and technological processes influence the maturity of the system. In turn, maturity influences how quality factors interact with information use, as a measure of success.

Research shows that system maturity also plays an essential role in understanding system success (Chuah \& Wong, 2011). Though partial correlation analysis does not explain causality, the strong significance in the relationship between the quality constructs and information use indicates that these variables are closely linked. As a result, the conclusions found in this study's findings cannot be interpreted as determining the cause of system success, but the findings do expand the body of knowledge through an increased understanding of the relationship between the constructs of quality, maturity, and information use.

\subsection{Limitations}

The study included a sample of business intelligence users in the form of senior executives. The participants represented individuals responsible for operations, data analysis, decision making, and management. The survey focused on a broad sample of industry tasks, and this general approach could have affected participants' responses and may explain the very strong correlation between the independent and dependent constructs. The broadness of the target population, focusing on senior executives in a range of industries did not allow me to draw insights into specific trends in business intelligence systems use in specific industries or sectors. A more focused study would allow for more targeted conclusions regarding business intelligence system use in specific industry settings.

Though the results of the presented study met expectations, the study was limited in that it analyzed the relationship between the dependent and independent constructs but did not explain causality. The results of the study showed a strong relationship amongst the constructs pointing for a need for further research regarding the causality of business intelligence success based on quality success factors. The results of the study showed that there are links between technological and organizational processes and the perception of quality in the use of a business intelligence system. The significance of including maturity in the study uncovered a need to understand further how technological readiness and analytical processes interact with quality factors to influence information use. This finding coincides with recent studies which point to a need to account for organizational processes (Fink et al., 2017; Trieu, 2017).

\subsection{Implications for Practice}

The results of this study have strong implications for practice regarding both scholars and practitioners. From a scholarly perspective, the study's findings both confirm pre-existing theories and extend the avenues of future research. The data analysis indicated that quality factors are closely linked with information use as a measure of success. These results verify prior results by Kowalczyk and Buxmann (2014) and Visinescu et al. (2016). By demonstrating the need to understand how quality factors influence system use and success, this study identified areas in need of additional research. Researchers should build off the study's findings and include other factors that may affect the perception of quality in the further analysis of business intelligence systems.

The analysis conducted in this study highlights that maturity factors have a moderate to strong influence on the relationship between information and system quality and information use. 
Organizational and technological processes, measured in the context of maturity, have been shown to influence the perceptions of quality within an organization (Seddon et al., 2017). Findings such as these suggest a need to consider additional factors that moderate system and information quality (Olszak, 2016). The present study can serve as a starting point for scholars interested in extending the literature on business intelligence system success.

From the perspective of practitioners, the study offered important insights. Prior studies determined that information quality has a strong influence in the use of information in a business intelligence system (Dooley, 2015), but the findings related to system quality were inconclusive (Popovič et al., 2014). In comparison, the analysis conducted in this study verified the importance of information quality but also showed a strong relationship between system quality and information use. The study's findings mean that organizations that have higher quality systems and use higher quality information are more likely to be successful. Thus, to truly benefit from the implementation of a business intelligence system, organizations should concentrate on quality rather than quantity, speed, or diversity.

The study's results also suggested that the perceptions of information and system quality are influenced by other factors related to maturity. This study measured the influence of maturity as a moderating factor and concluded that the maturity of the business intelligence system may have an indirect but important influence on system success as measured by information use. The implication for practitioners is that as systems become more mature, they increase in quality and become more successful. This finding indicates that organizations should not abandon a newly implemented system in the early stages if it is not meeting expectations, as the system may become more successful as it matures.

\subsection{Recommendations for Further Research}

Future research should focus on expanding the study to large organizations operating outside the United States. This approach would allow researchers to examine a more varied sample that is representative of the global nature of today's business environment. Organizations could benefit from understanding how information use is affected by quality factors outside their particular region (Rouhani et al., 2016). Conducting a global study could provide useful insights into how quality factors influence information use in other countries and regions due to differences in technology, maturity, and implementation practices. Data used by business intelligence systems comes from everywhere in the world. Both the present study and the study by Popovič et al. (2014) analyzed populations from a single nation. The increasing use of business intelligence systems across medium and large organizations merits a study that analyzes system success from a multinational perspective.

Though the relationships between the constructs were strong, the correlation analysis did not determine the causes of business intelligence system success. Thus, to determine causality, further research is needed. Additionally, business intelligence system complexity requires researchers to focus on additional factors that might influence quality (Vallurupalli \& Bose, 2018). A review of the literature demonstrated a need to include organizational processes as part of the analysis (Kowalczyk \& Buxmann, 2014). Results of the study show that maturity influences the relationship between quality factors and the success of the system. Organizational and technological processes have also been shown to influence the perception of quality within an organization (Seddon et al., 2017). The inclusion of maturity factors to moderate the relationship between quality constructs and information use showed a need to further explore the types of processes influencing business intelligence systems. 
Finally, there are business value areas that have the potential to influence the success of business intelligence systems (Trieu, 2017). Research shows a need to understand how to measure the value creation capability of the business intelligence system (Fink et al., 2017). Fink et al. pointed to a need for research on specific value creation processes such as system assets, capabilities, organizational resources, and business value to determine how these processes affect system success (Fink et al., 2017). Additional research in the area of value creation can contribute to a better understanding of successful business intelligence system implementation and use.

\subsection{Conclusion}

The study aimed to understand the relationship between quality factors and the successful use of business intelligence systems. The population of interest for this study was senior executives in U.S. organizations that use business intelligence systems to make decisions. Due to the highly complex nature of business intelligence systems, these systems are rarely implemented in a way that allows organizations to realize their full potential (Popovič et al., 2012, 2014). This complexity can also make measuring system success difficult.

The study contributed to the body of knowledge by documenting the significance ofthe relationships between quality factors and business intelligence system success as measured by information use. Similar to previous studies, information quality was found to be significantly linked to information use as a measure of system success. Additionally, the current analysis found that system quality was also positively related to information use, a link that was inconclusive in the earlier study by Popovič et al. (2014).

In addition to studying the direct relationships between quality and information use, the study also examined the moderating effects of maturity factors on business intelligence systems success. The results of the study highlighted that the complexity of technology used in a business intelligence system calls for the additional analysis of maturity factors that influence both quality and system use. The results of the study confirmed prior research by Grublješič and Jaklič (2015) by showing that additional processes influence the quality and use of business intelligence systems.

The perception of quality in a business intelligence system is related to the information content as perceived by its intended user (Peters, Iş̧1k, Tona, \& Popovič, 2016). Though the study provided additional evidence that the IS success model developed by Delone and McLean (2003) provides a solid foundation to understand business intelligence system success, additional factors must be considered to understand and evaluate the use of business intelligence systems adequately. This study supports the importance of business intelligence systems and demonstrates that success, as measured by information use, has a strong relationship with both quality and maturity factors.

\section{REFERENCES}

[1] Adamala, S., \& Cidrin, L. (2011). Key success factors in business intelligence. Journal of Intelligence Studies in Business, 1, 107-127. Retrieved from https://ojs.hh.se/index.php/JISIB/index

[2] Appelbaum, D., Kogan, A., Vasarhelyi, M., \& Yan, Z. (2017). Impact of business analytics and enterprise systems on managerial accounting. International Journal of Accounting Information Systems, 25(Supplement C), 29-44. doi:/10.1016/j.accinf.2017.03.003

[3] Arnott, D., Lizama, F., \& Song, Y. (2017). Patterns of business intelligence systems use in organizations. Decision Support Systems, 97, 58-68. doi:10.1016/j.dss.2017.03.005

[4] Bach, M. P., Čeljo, A., \& Zoroja, J. (2016). Technology acceptance model for business intelligence systems: Preliminary research. Procedia Computer Science, 100, 995-1001. doi:10.1016/j.procs.2016.09.270 
[5] Baker, E., \& Chasalow, L. (2015). Factors contributing to business intelligence success: The impact of dynamic capabilities. In Twenty-first Americas Conference on Information Systems (Vol. 1, pp. 670-682). Red Hook, NY: Curran Associates.

[6] Castellanos, M., Gupta, C., Wang, S., Dayal, U., \& Durazo, M. (2012). A platform for situational awareness in operational BI. Decision Support Systems, 52, 869-883. doi:10.1016/j.dss.2011.11.011

[7] Chuah, M. H., \& Wong, K. L. (2011). A review of business intelligence and its maturity models. African Journal of Business Management, 5, 3424-3428. doi:10.5897/AJBM10.1564

[8] DeLone, W. H., \& McLean, E. R. (2003). The DeLone \& McLean model of information systems success: A ten-year update. Journal of Management Information Systems, 19(4), 9-30. doi:10.1080/07421222.2003.11045748

[9] DeLone, W. H., \& McLean, E. R. (2016). Information systems success measurement. Foundations and Trends ${ }^{\circledR}$ in Information Systems, 2(1), 1-116. doi:10.1561/2900000005

[10] Dooley, P. P., Levy, Y., Hackney, R. A., \& Parrish, J. L. (2018). Critical value factors in business intelligence systems implementations. In A. V. Deokar, A. Gupta, L. S. Iyer, \& M. C. Jones (Eds.), Analytics and data science: Annals of information systems (pp. 55-78). Cham, Switzerland: Springer.

[11] Even, A., Parmet, Y., \& Erez, L. (2015). Factors that affect customers readiness for internet-based BI services. International Journal of Business Intelligence Research, 6(1), 30-48. doi:10.4018/IJBIR.2015010103

[12] Eybers, S., \& Giannakopoulos, A. (2015). Identifying critical success factors for business intelligence systems. In E. Pimenidis, \& M. Odeh (Eds.), Proceedings of the 9th European Conference on IS Management and Evaluation (pp. 77-84). Reading, England: Academic Conferences and Publishing International.

[13] Farrokhi, V., \& Pokoradi, L. (2012). The necessities for building a model to evaluate business intelligence projects-literature review. International Journal of Computer Science \& Engineering Survey, 3(2), 1-10. doi:10.5121/ijcses.2012.3201

[14] Fink, L., Yogev, N., \& Even, A. (2017). Business intelligence and organizational learning: An empirical investigation of value creation processes. Information \& Management, 54(1), 38-56. doi:10.1016/j.im.2016.03.009

[15] Fornell, C., \& Larcker, D. F. (1981). Evaluating structural equation models with unobservable variables and measurement error. Journal of Marketing Research, 18, 39-50. doi:10.2307/3151312

[16] Foshay, N., Taylor, A., \& Mukherjee, A. (2014). Winning the hearts and minds of business intelligence users: The role of metadata. Information Systems Management, 31, 167-180. doi:10.1080/10580530.2014.890444

[17] Gaardboe, R., \& Svarre, T. (2017). Critical factors for business intelligence success. Proceedings of the 25th European Conference on Information systems (ECIS), 2017, 471-482. Retrieved from http://aisel.aisnet.org/ecis2017_rp/31

[18] Grublješič, T., \& Jaklič, J. (2015). Business intelligence acceptance: The prominence of organizational factors. Information Systems Management, 32, 299-315. doi:10.1080/10580530.2015.1080000

[19] Hackney, R., Dooley, P., Levvy, Y., \& Parrish, J. (2015). Critical value factors in business intelligence systems implementation success: An empirical analysis of system and information quality. Paper presented at the 2015 International Conference on Information Systems, Ft. Worth, Texas. Retrieved from http://bura.brunel.ac.uk/handle/2438/11970

[20] Hair, J. F., Jr. (2016). A primer on partial least squares structural equation modeling (2nd ed.). Retrieved from https://bookshelf.vitalsource.com/books/9781483377469

[21] Keith, T. Z. (2015). Multiple regression and beyond: An introduction to multiple regression and structural equation modeling (2nd ed.). New York, NY: Routledge.

[22] Kowalczyk, M., \& Gerlach, J. P. (2015). Business intelligence \& analytics and decision quality Insights on analytics specialization and information processing modes. ECIS 2015 Completed Research Papers, Paper 110. doi:10.18151/7217398

[23] Kowalczyk, M., \& Buxmann, P. (2014). Big data and information processing in organizational decision processes. Business \& Information Systems Engineering, 6, 267-278. doi:10.1007/s12599014-0341-5

[24] Mardiana, S., Tjakraatmadja, J. H., \& Aprianingsih, A. (2015). DeLone-McLean information system success model revisited: The separation of intention to use-use and the integration of technology 
acceptance models. International Journal of Economics and Financial Issues, 5(1S), 172-182. Retrieved from http://www.econjournals.com/index.php/ijefi/index

[25] Olszak, C. M. (2016). Toward better understanding and use of business intelligence in organizations. Information Systems Management, 33, 105-123. doi:10.1080/10580530.2016.1155946

[26] Peters, T., Işık, Ö., Tona, O., \& Popovič, A. (2016). How system quality influences mobile BI use: The mediating role of engagement. International Journal of Information Management, 36, 773-783. doi:10.1016/j.ijinfomgt.2016.05.003

[27] Popovič, A., Coelho, P. S., \& Jaklič, J. (2009). The impact of business intelligence system maturity on information quality. Information Research, 14(4), Article 417. Retrieved from http://www.informationr.net/ir/index.html

[28] Popovič, A., Hackney, R., Coelho, P. S., \& Jaklič, J. (2012). Towards business intelligence systems success: Effects of maturity and culture on analytical decision making. Decision Support Systems, 54, 729-739. doi:10.1016/j.dss.2012.08.017

[29] Popovič, A., Hackney, R., Coelho, P. S., \& Jaklič, J. (2014). How information-sharing values influence the use of information systems: An investigation in the business intelligence systems context. The Journal of Strategic Information Systems, 23, 270-283. doi:10.1016/j.jsis.2014.08.003

[30] Rouhani, S., Ashrafi, A., Zare Ravasan, A., \& Afshari, S. (2016). The impact model of business intelligence on decision support and organizational benefits. Journal of Enterprise Information Management, 29, 19-50. doi:10.1108/JEIM-12-2014-0126

[31] Seddon, P. B., Constantinidis, D., Tamm, T., \& Dod, H. (2017). How does business analytics contribute to business value? Information Systems Journal, 27, 237-269. doi:10.1111/isj.12101

[32] Torres, R., Sidorova, A., \& Jones, M. C. (2018). Enabling firm performance through business intelligence and analytics: A dynamic capabilities perspective. Information \& Management, 55, 822839. doi:10.1016/j.im.2018.03.010

[33] Trieu, V. H. (2017). Getting value from business intelligence systems: A review and research agenda. Decision Support Systems, 93, 111-124. doi:10.1016/j.dss.2016.09.019

[34] Vallurupalli, V., \& Bose, I. (2018). Rabbit or tortoise? Rethinking customer acquisition at Dravya Bank. Communications of the Association for Information Systems, 43, Article 22. doi:10.17705/1CAIS.04322

[35] Visinescu, L. L., Jones, M. C., \& Sidorova, A. (2016). Improving decision quality: The role of business intelligence. The Journal of Computer Information Systems, 57, 58-66. doi:10.1080/08874417.2016.1181494

[36] Wixom, B., \& Todd, P. A. (2005). A theoretical integration of user satisfaction and technology acceptance. Information Systems Research, 16(1), 85-102. doi:10.1287/isre.1050.0042

[37] Yeoh, W., \& Koronios, A. (2010). Critical success factors for business intelligence systems. The Journal of Computer Information Systems, 50(3), 23-32. Retrieved from https://www.tandfonline.com/loi/ucis20

[38] Yeoh, W., Koronios, A., \& Gao, J. (2008). Managing the implementation of business intelligence systems: A critical success factors framework. International Journal of Enterprise Information Systems, 4(3), 79-94. doi:10.4018/jeis.2008070106

[39] Yeoh, W., \& Popovič, A. (2016). Extending the understanding of critical success factors for implementing business intelligence systems. Journal of the Association for Information Science \& Technology, 67(1), 134-147. doi:10.1002/asi.23366 